\title{
Retraction of Frame Building the "Social Digitization" in the German Press
}

\section{Pablo Porten-Cheé *}

Issue Date

Original Article
29 Nov 2020

Porten-Cheé, P. (2017). Frame Building the "Social Digitization" in the German Press. Online Journal of Communication and Media Technologies, 7(4), 96-117. https://doi.org/10.29333/ojcmt/2612

This document states that the Original Article is retracted by authors' request.
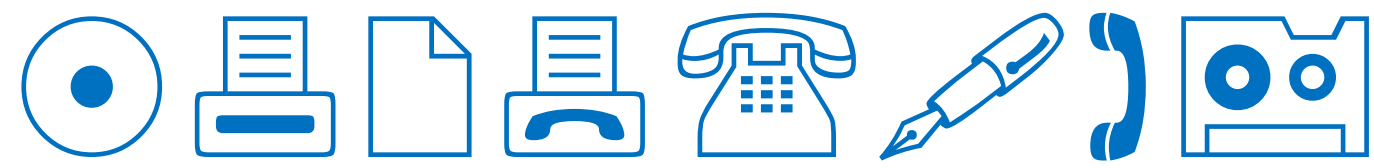

Copyright (c) $\mathbf{2 0 2 0}$ by authors; licensee OJCMT. This article is an open access article distributed under the terms and conditions of the Creative Commons Attribution License (http://creativecommons.org/licenses/by/4.0/). 